\title{
Hubungan Sistem Transportasi Dump Truck pada Pengangkutan Tandan Buah Segar ke Pabrik Kelapa Sawit
}

\author{
Relationship of Dump Truck Transportation System on Fresh Fruit Fruits Transportation \\ to Palm Oil Factory
}

\author{
Sri Ngapiyatun ", Zikri Kurniadi, Nur Hidayat, Budi Winarni, Ernita Obeth \\ Politeknik Pertanian Negeri Samarinda, JI. Samratulangi PO BOX 192 Samarinda, Indonesia
}

${ }^{*}$ Corresponding Author: zikrikurniadi@gmail.com

\begin{abstract}
Abstrak
Penelitian ini dilatarbelakangi oleh keingintahuan peneliti terhadap sistem transportasi pada pekerbunan kelapa sawit terkait hubungan dengan jumlah muatan Tandan Buah Segar (TBS) yang diangkut dilihat dari kecepatan laju transportasi serta waktu tempuh transportasi. Tujuan dilakukan penelitian ini mengenalisa sistem transportasi pada pengangkutan TBS, dan variabel-variabel yang mempengaruhinya: studi kasus pada PT. Hanusentra Agro Lestari dalam proses pengangkutan TBS pada lingkup Divisi di perusahaan. Metode pengumpulan data yang digunakan berupa data primer meliputi: pengamatan serta observasi, pengambilan data lapangan, dokumentasi, dan wawancara. Data sekunder berupa dokumen perusahaan yang berkaitan dengan transportasi. Penelitian ini menggunakan sampling jenuh. Analisis data yang digunakan adalah deskriptif untuk memperoleh data yang bersifat apa adanya yang menekankan makna dari nilai data penelitian tersebut dengan menggunakan korelasi pearson serta uji normalitas. Hasil dari penelitian menunjukkan bahwa sistem transportasi yang digunakan di PT. Hanusentra Agro Lestari menggunakan pengangkutan sistem bin, sistem tersebut merupakan sistem kontrol yang dilakukan oleh manajemen guna mempermudah pekerjaan pada proses pengangkutan, terdapat hubungan negatif pada variabel TBS dengan variabel kecepatan, berhubungan positif pada variabel TBS dan waktu tempuh, serta terdapat hubungan antara waktu tempuh dan kecepatan transportasi pada muatan TBS yang diangkut ke PKS.
\end{abstract}

Kata Kunci: Transportasi, Dump Truck, Pengangkutan, TBS

\begin{abstract}
The aim of this research is to analyze the relationship between the amount of palm fresh fruit bunch (FFB) loaded on a drump truck, speed of the truck, and travel time. The research was carried out in PT. Hanusentra Agro Lestari. Primary data was collected through observation, field data, and documents, interview whereas secondary the data related to transportation was provided by the company. Saturated sampling method was used to collect all related data. Data was then analyzed using pearson correlation and normality test. Result shows that PT. Hanusentara Agro Lestari uses bin system transportation which the management uses to control loading process. Data analysis shows that there is a negative relationship between the amount of palm FFB loaded and the truck speed whereas the relationship between the amount of palm FFB loaded and travel time is positive. This means an increase in the amount of palm FFB loaded leads to a decrease in truck speed and an increase in travel time.
\end{abstract}

Keywords: Transportation, DumpTruck, Transportation, Palm FFB

\section{PENDAHULUAN}

Indonesia dikenal dengan sebutan negara agraris oleh banyak negara di Eropa karena sebagian besar penduduknya bekerja sebagai petani. Data Badan Pusat Statistik (BPS) Agustus 2019 mencatat penduduk Indonesia yang bekerja di sektor pertanian sebesar 34,58 juta orang atau $27,33 \%$ dari jumlah penduduk yang bekerja sebesar 160,24 juta orang.

Produk Domestik Bruto (PDB) pada Triwulan II tahun 2019 menunjukkan sektor pertanian penyumbang ke dua terbesar di Indonesia yaitu $14,10 \%$ setelah sektor industri sebesar 20,38\%. Sektor pertanian terbagi atas sub sektor yaitu: pertanian (tanaman pangan \& hortikultura, perkebunan. 
Dari sub sektor tersebut katagori
tanaman pangan dan perkebunan
merupakan lapangan usaha yang memberikan kontribusi terbesar dalam pembentukan PDB yaitu sebesar 9,09\% dari total sektor pertanian $14.10 \%$ diikuti sub sektor kehutanan 2,86\% dan perikanan sebesar 1,85\% (Anonim, 2019b). Salah satu primadona tanaman perkebunan yaitu kelapa sawit dari pembangunan sub sektor kelapa sawit merupakan penyedia lapangan kerja yang cukup besar dan sebagai sumber pendapatan petani. Kelapa sawit merupakan salah satu komoditas yang memiliki andil besar dalam menghasilkan pendapatan hasil daerah, produk domestik bruto, dan kesejahteraan masyarakat (Afifuddin, 2007).

Pada umumnya alat transportasi pengangkutan tandan buah segar di perkebunan kelapa sawit biasanya menggunakan transportasi roda empat atau lebih dengan berbagai jenis transportasi pengangkutan di dalamnya seperti Landiri, Jhondere, dan Dump Truck. Di dalam perkebunan sendiri banyak menggunakan berbagai macam jenis transportasi dengan sistem pengangkutan yang berbeda dan terbagi menjadi dua bagian pengantaran yaitu pengantaran langsung dan tidak langsung. Pengantaran langsung (direct) adalah proses pengangkutan TBS dari Tempat Pengumpulan Hasil (TPH) langsung ke Pabrik Kelapa Sawit (PKS). Sedangkan pengantaran tidak langsung (indirect) merupakan proses pengangkutan TBS dari TPH yang berhenti di stampingan (loading ramp afdeling ) lalu dilanjut ke PKS oleh unit transportasi yang berbeda oleh perusahaan (Tammara, 2012).

Penelitian ini bertujuan mengetahui sistem transportasi apa yang digunakan untuk pengangkutan Tandan Buah Segar serta mengetahui ada atau tidak hubungan antara variabel yang diteliti (kecepatan dan waktu tempuh transportasi dengan TBS) pada PT. Hanusentra Agro Lestari.

\section{METODE PENELITIAN}

\section{A. Waktu dan Tempat Penelitian}

Penelitian ini dilaksanakan di PT. Hanusentra Agro Lestari yang berada di Desa Kelolokan Kecamatan Sangkulirang, Kutai Timur Kalimantan Timur. Kegiatan ini dilakukan selama kurang dari 2 bulan dimulai pada tanggal 14 September - 31 Oktober pada tahun 2020. Penelitian yang dilakukan meliputi kegiatan teknis dan manajerial di lapangan, analisis data berupa laporan, pedoman kerja dan sebagainya yang terkait dengan proses kegiatan transportasi pengangkutan oleh unit dump truck yang ada di perusahaan disertai penyusunan laporan.

\section{B. Alat dan Bahan}

Alat yang digunakan adalah alat tulis, lembar observasi, kamera, stopwatch dan alat transportasi yang digunakan selama pengambilan data. Sedangkan bahan yang digunakan adalah TBS kelapa sawit yang diangkut.

\section{Prosedur Penelitian}

1. Mempersiapkan alat dan bahan yang digunakan dalam penelitian.

2. Melakukan diskusi kepada pembimbing di lapangan mengenai transportasi pengangkutan TBS oleh unit dump truck dan data yang diambil dengan lembar observasi da lembar kuesioner.

3. Meminta arahan dan jadwal yang pas untuk mengikuti kegiatan pengangkutan di lapangan serta meminta izin kepada sopir transportasi untuk mengajukan pertanyaan dalam bentuk tertulis.

4. Menyiapkan lembar observasi untuk pengambilan data yang telah dirancang dan dimasukkan ke dalam lembar observasi dalam proses kegiatan pengangkutan berlangsung serta mengikuti kegiatan sampai dengan selesai.

5. Pada waktu istirahat kegiatan dalam proses pengangkutan ketika sopir ada waktu luang maka meminta izin dan melakukan proses diskusi dan menyerahkan lembar kuesioner untuk diisi oleh sopir transportasi, yang diharapkan sopir dapat mengisi data yang sebenarnya sesuai dengan arahan yang tertulis

6. Setelah semua data didapatkan yaitu data berupa observasi dan kuesioner maka dipisah lembar tersebut dan di catat kembali dalam lembar penulisan agar lebih jelas.

7. Ketika semua sudah selesai dipisah dan dirapikan kemudian data tersebut akan dilakukan uji korelasi. 
Tabel 1. Ketentuan Sistem Traksi yang Diterapkan di PT.HAL

\begin{tabular}{cccc}
\hline No & Uraian & Divisi III & Divisi V \\
\hline 1 & Asisten Traksi & M. Azizwan & M. Azizwan \\
2 & Mandor Traksi & Azahri E. & Azahri E. \\
3 & Tipe DT & Toyota Dyna 130 HT & Toyota Dyna 130 \\
4 & Sistem muatan & Bin & HT \\
5 & Umur kendaraan & 2016/2017 & 2016/2017 \\
6 & Jumlah DT yang diteliti & 4 & 4 \\
7 & Basis muatan & 12 Ton & 12 Ton \\
8 & Kapasitas max muatan & 6 Ton & 6 Ton \\
9 & Waktu kerja DT & 9-12 Jam & 9-12 Jam \\
10 & Pengisian solar per/Hari & 25-35 Liter & 25-35 Liter \\
\hline
\end{tabular}

\section{HASIL DAN PEMBAHASAN}

\section{A. Sistem Transportasi}

Berdasarkan hasil penelitian yang dilakukan dari hasil wawancara dan pengamatan di kebun PT. Hanusentra Agro Lestari (HAL) khususnya di Divisi III dan V adalah sistem bin atau muatan langsung yang diangkut oleh pemuat (peloading) pada Tabel 1.

Bin system adalah suatu sistem untuk mengangkut TBS yang sudah dipanen menuju ke pabrik kelapa sawit untuk diolah. Sistem ini terdiri dari dua kendaraan pengangkut dan bin. Kendaraan pengangkut pertama adalah scissor lift, Bin yang berkapasitas 9 ton akan penuh dengan 4-5 trip scissor lift. Sistem bin didefinisikan sebagai suatu sistem yang terdiri dari fasilitas tertentu beserta arus dan sistem kontrol yang memungkinkan orang atau barang dapat berpindah dari suatu tempat ke tempat lain secara efisien dalam setiap waktu untuk mendukung aktivitas manusia dimana manusia menjadi pengendali yang aktif dalam hal merencanakan kebutuhan (Miro, 2012).

\section{B. Deskripsi Hasil Penelitian}

Berdasarkan hasil penelitian yang dilakukan bertujuan untuk melihat apakah adanya hubungan waktu tempuh atau kecepatan laju transportasi dengan muatan TBS yang diangkut dapat dilihat di bawah ini: 1. Pengujian Normalitas

Pengujian normalitas dilakukan untuk mengetahui 3 variabel bersifat normal atau tidak sebagai syarat dari ketentuan dari analisis korelasi pearson pada penelitian ini yang dapat dilihat pada Tabel 2.

2. Pengujian Korelasi

Digunakan untuk mengetahui ada atau tidak hubungan dari variabel kecepatan dan waktu perjalanan transportasi dengan muatan TBS yang diangkut, ada atau tidaknya hubungan tersebut tidak selalu berarti adanya hubungan kausalitas yang berarti sebab dan akibat. Hasil uji dapat di lihat pada tabel 3.

Transportasi dump truck yang digunakan oleh Divisi III dan V berjumlah 8 (delapan) kendaraan dengan 8 (delapan) sopir, dimana pengaturan transportasi diatur oleh asisten Divisi masing-masing yang akan diteruskan kepada asisten traksi. Untuk mencari hubungan antara kecepatan \& waktu tempuh transportasi dengan muatan TBS yang diangkut maka dilakukan uji normalitas pada variabel tersebut, untuk melanjutkan ke analisis korelasi pearson berikutnya.

Tabel 2. Hasil Tests of Normality

\begin{tabular}{ccccc}
\hline Variabel & $\begin{array}{c}\text { Descriptive } \\
\text { Statistic }\end{array}$ & Df & Signifikansi & Keterangan \\
\hline Waktu & 0.792 & 24 & $0.134^{\mathrm{a}}$ & Normal \\
TBS & 0.902 & 24 & $0.262^{\mathrm{a}}$ & Normal \\
Kecepatan & 0.914 & 24 & $0.196^{\mathrm{a}}$ & Normal \\
\hline
\end{tabular}

Dari tabel di atas menunjukkan ketiga variabel penelitian yaitu waktu, TBS, dan kecepatan sama-sama bernilai Normal 
karena nilai Sig. dengan angka bertanda ${ }^{a}$ berada pada nilai $>0,05$ sehingga nilai dari variabel kecepatan transportasi, TBS, dan waktu perjalanan dikatakan normal.

Berdasarkan data yang diperoleh dari hasil lembar observasi yang digunakan serta dianalisis menggunakan SPSS for Windows versi 25 , dari tiga variabel yang digunakan yaitu TBS, kecepatan dan waktu tempuh transportasi sebagai berikut:

\begin{tabular}{|c|c|c|c|c|}
\hline & \multicolumn{4}{|c|}{ Correlations } \\
\hline & & TBS & Kecepatan & Waktu \\
\hline \multirow{3}{*}{ TBS } & Pearson Correlation & 1 & -0.571 & 0.326 \\
\hline & Sig. (2-tailed) & 0 & 0.009 & 0.006 \\
\hline & $\mathrm{N}$ & 24 & 24 & 24 \\
\hline \multirow{3}{*}{ Kecepatan } & Pearson Correlation & -0.571 & 1 & -0.214 \\
\hline & Sig. (2-tailed) & 0.009 & 0 & 0.016 \\
\hline & $\mathrm{N}$ & 24 & 24 & 24 \\
\hline \multirow{3}{*}{ Waktu } & Pearson Correlation & 0.326 & -0.214 & 1 \\
\hline & Sig. (2-tailed) & 0.006 & 0.016 & 0 \\
\hline & & 24 & 24 & 24 \\
\hline
\end{tabular}

Dari output variabel TBS diketahui nilai korelasi dengan variabel kecepatan sebesar $-0,571$ (Negatif) dengan nilai signifikan (2tailed) adalah $0,009<0,05$ (nilai syarat $\mathrm{H} 0$ \& H1 diterima) maka dapat di simpulkan bahwa ada hubungan yang negatif dan signifikan. Nilai Negatif menyatakan hubungan terbalik yang berarti jika TBS yang diangkut meningkat maka kecepatan transportasi akan menurun, sedangkan nilai korelasi sebesar 0,571 menunjukkan tingkat hubungan sedang.

Dari output variabel TBS diketahui nilai korelasi dengan variabel waktu sebesar 0,326 (Positif) dengan nilai signifikan (2tailed) adalah 0,006 < 0,05, maka dapat disimpulkan ada hubungan yang positif dan signifikan. Nilai positif menyatakan hubungan searah yang berarti jika TBS yang diangkut meningkat maka waktu tempuh akan meningkat, sedangkan nilai korelasi 0,326 dengan tingkat hubungan rendah.

Dari output variabel kecepatan diketahui nilai korelasi dengan variabel waktu sebesar 0,214 (Negatif) dengan nilai signifikan (2tailed) adalah 0,016 < 0,05, maka dapat di simpulkan ada hubungan yang negatif dan signifikan.

Nilai negatif menyatakan hubungan terbalik yang berarti jika kecepatan meningkat maka waktu tempuh transportasi
Menurun, sedangkan nilai korelasi $-0,214$ dengan tingkat hubungan rendah.

\section{Kondisi Jalan Divisi}

Bentuk kondisi jalan juga menjadi salah satu faktor penting keberhasilan pengelolaan pengangkutan TBS dari keadaan jalan yang dilalui oleh kendaraan pengangkut. Dari informasi dan hasil pengamatan di lapangan untuk jalan utama maupun jalan blok dengan kondisi yang dapat dilihat pada Tabel 4 .

Tabel 4. Kondisi jalan Divisi \& Blok Tahun 2020.

\begin{tabular}{cccc}
\hline & \multicolumn{3}{c}{ Kondisi Jalan Rusak } \\
\cline { 2 - 4 } Divisi & $\begin{array}{c}\text { Panjang } \\
\text { Jalan Rusak }\end{array}$ & $\begin{array}{c}\text { Jalan } \\
\text { utama }\end{array}$ & $\begin{array}{c}\text { Jalan } \\
\text { blok }\end{array}$ \\
\hline III & $1300 \mathrm{~m}$ & $400 \mathrm{~m}$ & $900 \mathrm{~m}$ \\
V & $1900 \mathrm{~m}$ & $700 \mathrm{~m}$ & $1200 \mathrm{~m}$ \\
\hline
\end{tabular}

Dari hasil observasi yang dapat dilihat pada Tabel, 4 terhadap kondisi jalan yang ada dapat dijelaskan bahwa rata-rata kondisi jalan yang rusak pada Divisi 3 adalah 1300 m dan pada Divisi 5 adalah 1900 m. Pihak manajemen selalu melakukan evaluasi atau perbaikan berkelanjutan untuk mengurangi jalan yang rusak tiap tahunnya demi kelancaran proses pengantaran TBS. Sesuai dengan pendapat Sastrosayono (2008) yang menyatakan bahwa sistem jaringan jalan di kawasan kebun merupakan salah satu faktor penting untuk mengumpulkan dan mengangkut hasil kelapa sawit ke pabrik. Selain itu, jaringan jalan yang baik bisa menjamin kelancaran pengangkutan pupuk dan bahan lainnya, banyaknya areal atau blok di kebun tidak dapat dikerjakan secara lancar karena prasarana jalan atau jembatan kurang memadai, dan kegiatan oprasional menjadi terhambat.

\section{Kondisi \& Perawatan Alat Transportasi}

Transportasi yang dibutuhkan untuk pengangkutan TBS harus selalu dalam kondisi optimal maka dari itu pihak manajemen khususnya bagian traksi selalu memperhatikan kendaraan setiap hari dan melakukan servis rutin tiap minggu untuk melakukan pengecekan kendaraaan dimana setiap kendaraan memiliki jadwal tertulis di papan tulis, dokumen, dan juga diberikan 
Tabel 5. Kondisi \& Perawatan Alat Transportasi

\begin{tabular}{|c|c|c|c|c|c|c|}
\hline \multirow{2}{*}{ Divisi } & \multirow{2}{*}{$\begin{array}{l}\text { No. } \\
\text { Unit }\end{array}$} & \multirow{2}{*}{ No. KT } & \multicolumn{2}{|c|}{ Kondisi } & \multirow{2}{*}{$\begin{array}{l}\text { Hari } \\
\text { Service }\end{array}$} & \multirow{2}{*}{ Keterangan } \\
\hline & & & Baik & Rusak & & \\
\hline \multirow{4}{*}{ III } & DT 01 & $8415 \mathrm{NI}$ & $\sqrt{ }$ & - & Jumat & \multirow{8}{*}{$\begin{array}{c}\text { Ketika unit } \\
\text { mencapai } \\
\text { 6000km } \\
\text { dilakukan } \\
\text { pergantian oli } \\
\text { dan pengecekan } \\
\text { suku cadang dan } \\
\text { dijadwalkan bila } \\
\text { ada pergantian. }\end{array}$} \\
\hline & DT 02 & $8420 \mathrm{MU}$ & $\sqrt{ }$ & - & Jumat & \\
\hline & DT 03 & 8417 NI & $\sqrt{ }$ & - & Senin & \\
\hline & DT 08 & $8418 \mathrm{NI}$ & $\sqrt{ }$ & - & Selasa & \\
\hline \multirow{4}{*}{ V } & DT 05 & $8065 \mathrm{MU}$ & $\sqrt{ }$ & - & Sabtu & \\
\hline & DT 06 & $8978 \mathrm{MU}$ & $\sqrt{ }$ & - & Rabu & \\
\hline & DT 07 & 8416 NI & $\sqrt{ }$ & - & Senin & \\
\hline & DT 04 & $8481 \mathrm{NI}$ & $\sqrt{ }$ & - & Kamis & \\
\hline
\end{tabular}

tanda hari di belakang kendaraan dimana setiap Dump truck bagian belakangnya selalu ada nama hari yang tertulis. Karena kendaraan merupakan rantai yang berpengaruh pada pasokan TBS di pabrik. Hasil pengamatan bisa dilihat pada Tabel 5 .

Berdasarkan hasil pengamatan dan observasi yang dapat dilihat pada Tabel. 5 tentang kondisi serta perawatan dump truck memiliki kondisi prima 100\% dikarenakan pihak manajemen setiap 7 sampai dengan 10 tahun masa kendaraan maka akan dilakukan pergantian atau pertukaran unit sehingga biaya perawatan tidak terlalu besar untuk mobil tua. Pihak manajemen khususnya bagian traksi atau workshop membuat jadwal pada saat service dan pengecekan unit dump truck yaitu pada saat pagi setiap hari sebelum berangkat, lalu pada saat dump truck memasuki jadwal hari service setiap minggu dan juga pengecekan setiap kilometer kendaraan mencapai 6000 km.

Pihak manajemen sangat memperhatikan kondisi Dump truck yang ada di wiayah perusahaan agar mengurangi terjadinya kerusakan pada unit yang menyebabkan buah restan atau terlambatnya datang ke pabrik yang berpengaruh terhadap produktifitas pabrik itu sendiri. Setiap unit mempunyai kondisi perawatan yang berbedabeda. Pada setiap perawatan peneliti mengikuti alur kerja pengecekan tersebut dari yang hanya mengecek ban, oli, serta bahan bakar, hingga ke jadwal service perminggu. Asisten traksi selalu mengingatkan kepada sopir agar tidak melakukan pengangkutan buah di atas 6 ton sesuai ketentuan perusahaan agar tidak terjadi over load pada kapasitas bin yang menyebabkan dump truck terjadi kecelakaan.

\section{KESIMPULAN \& SARAN}

\section{A. Kesimpulan}

Berdasarkan hasil penelitian Hubungan Sistem Transportasi Dump Truck Pada Pengangkutan di PT. Hanusentra Agro Lestari (HAL) dapat disimpulkan bahwa :

1. Sistem transportasi yang digunakan di PT. Hanusentra Agro Lestari menggunakan pengangkutan sistem bin, sistem tersebut merupakan sistem kontrol yang dilakukan oleh manajemen guna mempermudah pekerjaan khususnya proses pengangkutan.

2. Terdapat hubungan negatif pada variabel TBS dengan variabel kecepatan, hubungan positif pada variabel TBS dan waktu tempuh, yang berarti ketika TBS yang diangkut meningkat maka kecepatan transportasi akan menurun serta waktu tempuh juga akan meningkat. Terdapatnya hubungan antara waktu tempuh dan kecepatan transportasi pada muatan TBS yang diangkut ke PKS.

\section{B. Saran}

Berdasarkan kesimpulan di atas, penulis ingin memberikan saran yaitu:

1. Pihak manajemen khususnya bagian traksi selalu memperhatikan jam kerja transportasi dimana proses kerja berlangsung acak menjadi serempak akan berpengaruh terhadap lamanya proses pengangkutan. 
2. Kinerja sopir transportasi sebaiknya lebih ditingkatkan agar pengaruh terhadap internal perusahaan agar jauh berkembang lebih baik lagi.

\section{DAFTAR PUSTAKA}

Abid. 2017. Karakteristik Tanaman Kelapa Sawit. Erlangga. Jakarta.

Afifuddin S. 2007. "Analisa Struktur Pasar CPO: Pengaruhnya Terhadap Pengembangan Ekonomi Wilayah Sumatra Utara." Jurnal Perencanaan dan Pengembangan Wilayah. Vol 2, No. 3:124-136.

Agrikita. 2019. Mekanisasi Pertanian Sawit Net System. https://agrikita.com/video/ mekanisasi-pertanian-sawit-net-system (diunduh 25 Maret 2020)

Aulia. 2018. Peranan Alat Transportasi Pengangkutan Tandan Buah Segar Dalam Memenuhi Kebutuhan Produksi Pengolahan Kelapa Sawit. Universitas Islam Negeri Sultan Syarif Kasim. Riau.

Anonim. 2019 . Keadaan Pekerja Indonesia Tahun 2019. https://www.bps.go.id/ publication/2019/11/29/c21630ee39b900 4459680923/keadaan-pekerja-diindonesia-agustus-2019.html (diunduh 09 April 2020).

Anonim. 2019 . Produk Domestik Bruto Inonesia Triwulanan 20152019.https://www.bps.go.id/publication/2 019/10/07/4923ba3ffd04cd25e83dcd97 /pdb-indonesia-triwulanan-20152019.html (diunduh 10 April 2020)

Derawan M.S., A. Hitam, dan Selamat M.B. 2004.Cableway System Far Oil Palm FFB

Evacuation. https://palmoilis.mpob.gov.my/publicatio ns/ToT/TT-218 (diunduh 20 Maret 2020)

Fauzi. 2007. Budidaya Kelapa Sawit. Penebar Swadaya. Jakarta.

Hartono A., Priyambodo, dan N. Kristalisasi. 2018. "Kajian Pengangkutan Panen Dengan Sistem Bin dan Sistem Net Di Perkebunan Kelapa Sawit”. Jurnal Agromast. Vol. 3, No. 1:5-14

Kurniawan, A. 2008. Belajar Mudah Untuk Spss Pemula. C.V. Andi. Yogyakarta.

Mangoensoekarjo. 2003. Manajemen Agrobisnis Kelapa Sawit. Gadjah Mada Universitas Press. Yogyakarta.

Miro F. 2007. Perencanaan Transportasi. Erlangga. Jakarta.
Miro F. 2012. Sistem Transportasi. Erlangga. Jakarta.

Nasution. 2008. Manajemen Transportasi. Ghalia Indonesia. Jakarta.

Pahan, I. 2008. Manajemen Agribisnis Dari Hulu Hingga Hilir. Penebar Swadaya. Jakarta.

Salim. 2000. Manajemen Transportasi. Ghalia Indonesia. Jakarta.

Sastrosayono, S. 2008. Budidaya Kelapa Sawit. Agromedia Pustaka. Purwokerto.

Simbolon M.M. 2003. Ekonomi Transportasi. Graha Indonesia. Jakarta.

Sulistyo. 2010. Budidaya Kelapa Sawit. Balai Pustaka PPKS. Jakarta.

Sugiyono. 2010. Metode Penelitian Pendidikan (Pendekatan kuantitatif, kualitatif dan R\&D. Alfabeta. Bandung.

Sunarko. 2009. Budidaya dan Pengelolaan Kebun Kelapa Sawit Dengan Sistem Kemitraan. Agromedia Pustaka. Jakarta.

Syahza. 2005. "Dampak Pembangunan Perkebunan Kelapa Sawit Terhadap Multiplier Effect Ekonomi Pedesaan". Jurnal ekonomi pembangunan. Vol. 12, No. 2:297-310

Tammara E.Y. 2012. Manajemen Pemanenan Tandan Buah Segar Kelapa Sawit. PT. Aneka Intipersada Minamas Plantation. Bogor 